\title{
$5-2015$
}

\section{The All-Digital Future and Digital CiSE}

George K. Thiruvathukal

Loyola University Chicago, gkt@cs.luc.edu

Follow this and additional works at: https://ecommons.luc.edu/cs_facpubs

Part of the Computer Sciences Commons

\section{Recommended Citation}

G. K. Thiruvathukal, "The All-Digital Future and Digital CiSE," in Computing in Science \& Engineering, vol. 17, no. 3, pp. 4-5, May-June 2015, doi: 10.1109/MCSE.2015.60.

This Article is brought to you for free and open access by the Faculty Publications and Other Works by Department at Loyola eCommons. It has been accepted for inclusion in Computer Science: Faculty Publications and Other Works by an authorized administrator of Loyola eCommons. For more information, please contact ecommons@luc.edu.

\section{(c) (1) $\Theta($}

This work is licensed under a Creative Commons Attribution-Noncommercial-No Derivative Works 3.0 License. 


\section{FROM THE EDITORS}

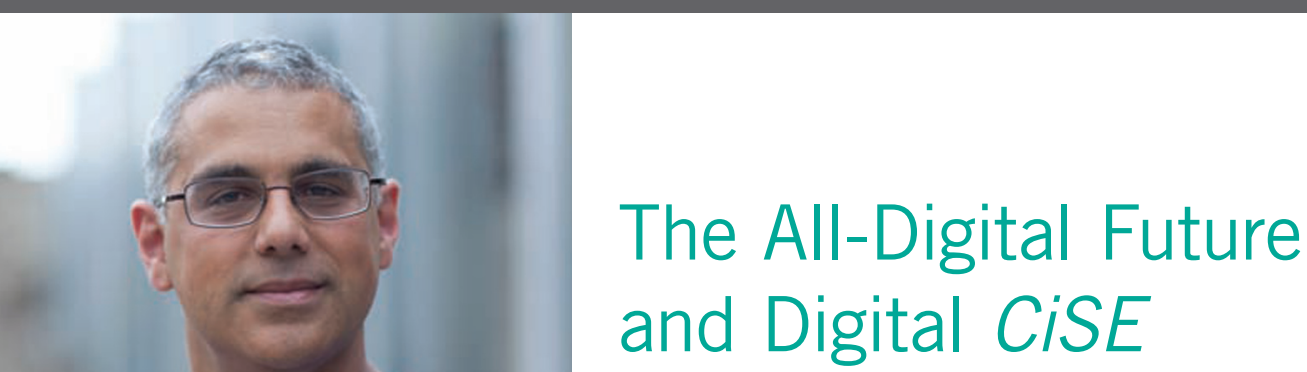

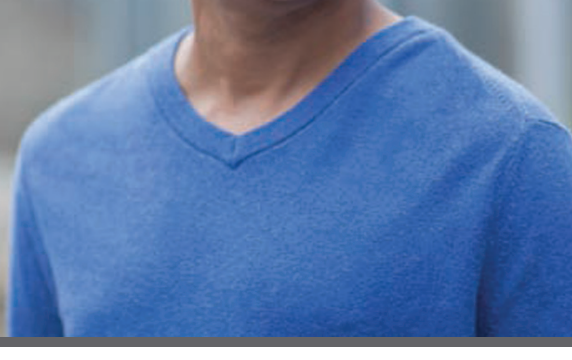

by George K. Thiruvathukal Loyola University Chicago
$\mathrm{V}$ int Cerf, widely considered to be one of the forefathers-or forepeople, in this age where we should be more oblivious to matters of gender, race, ethnicity, social status, and other forms of identification - of the Internet, created quite a stir recently. Specifically, he painted a dire picture of how we may be entering a "digital Dark age," with knowledge created during the 21 st century lost because of a rapidly accelerating digital revolution that brings about not only technological change but technological obsolescence (www.bbc.com/news/scienceenvironment-31450389). As we at Computing in Science \& Engineering and the IEEE Computer Society now find ourselves firmly entrenched in the digital era, where all artifacts are not only born digital but now live digital (http://en.wikipedia.org/wiki/ Born-digital), we realize we've entered a phase where there's likely to be no physical artifact of this magazine, unless someone intentionally decides to print a copy and file it in a library with dedicated long-term archival services. I have no idea whether this is happening or will indeed happen.

Cerf goes on to present an idea that ostensibly appears impossible and downright infeasible. We can only hope to preserve the knowledge from this era if we retain not only the digital artifacts but also the servers, systems, and applications that host them. We would essentially need to take an X-ray snapshot of every system, which would then be used to keep the "hardware" running (likely on virtual machines with the latest and greatest hardware/software). By doing so, we'd be virtually assured that any artifacts would remain available for an indefinite period. While it all sounds like science fiction, what he describes is essentially possible with current technology, but it's a vision that would require an extensive amount of capital to keep going in practice.

When reading Cerf's article, I was pleased to see that for the first time in my career, my intersections in two interdisciplinary areas (digital humanities and computational science) have finally found a way to intersect. In both circles, there's significant concern about what an all-digital future might portend. In an area known as textual studies, there's great interest not only in the work created but the process leading to a particular outcome. For example, in almost the same week as I read Cerf's admonitions, an article on c|net described a "hidden notebook" featuring Alan Turing's writings about codebreaking (and other tiny mathematical gems; www.cnet.com/news/rare-alan-turingjournal-shows-his-genius-at-work). Given my standing, presumably, as a representative, I'm perhaps in the last wave of folks who remember making handwritten notes about the crazy ideas circulating in my head.

Today, I still enjoy writing notes (mostly on napkins and coasters) but increasingly find most of my ideas living inside Google Documents or Trello (a nice brainstorming and planning tool that I use for a good number of projects). But I quiver at the thought of all this information "lost" someday when I move on from this planet to a different life (and lifestyle).

Beyond the digital humanities, there has also been a significant concern raised by the scientific computing community. For example, at the WSSSPE workshop (Working towards Sustainable Software for Science: Practice and Experience; http://wssspe. researchcomputing.org.uk), there has been significant discussion about the critical importance of preservation. Sure, we publish papers, but when it comes to scientific computing, a paper has many ingredients, including the datasets, the methods (math and science behind the work), and the code itself. Increasingly, we rely on the Internet 


\section{We can only hope to preserve the knowledge from this era if we retain not only the digital artifacts but also the servers, systems, and applications that host them.}

for each of these things. For example (focusing on the code), many of us use hosting services such as GitHub and Bitbucket. Will they be here tomorrow? I'd like to hope so, but we're increasingly at the mercy of the real world for much of what we do in computational science, and we need to think about the implications of this, especially from a sustainability standpoint.

This all circles me back to CiSE. As you know, we're firmly entrenched in the digital era. You no longer get CiSE in print, unless you specifically opt to pay for it at a much higher price. While for some individual subscribers this has been a bit disturbing (and disappointing), in some ways it was inevitable. The truth of the matter is that magazines and other publications (such as those for transactions and conferences) have pretty much been in the "born digital" era for some time now. As a smaller title, the vast majority of our readers - even those who subscribe individually-eventually find themselves going to the Internet and the Computer Society Digital Library to get their content. Even those who do prefer to read in print are more than likely to share a URL to the digital library, especially with someone else who wants to read a particular article. (I suppose you can share a digital version from your printed magazine by scanning and sending it off to someone, but this seems a bit inefficient, even to the dreaded casual observer that you might have read about in a physics textbook-or two.)

As an EIC, it thrills me to no end to know that people enjoy reading our articles through what are known as institutional subscriptions. (My own university subscribes to the CSDL, by the way.) One thing I wanted to do in conclusion is to make sure that you, our readers, know the various manifestations of digital. Individual subscribers receive a version known as Qmags format. Qmags is essentially what can be termed a "print facsimile," which basically means PDF_it's print ready and could even be taken to one of your favorite printing services, especially if you require a printed version. (I'm not saying this to make you feel better; I just want you to understand that the PDF you receive is essentially print ready and is optimized for print.)

Which takes me to my next point: what you receive isn't necessarily optimal for reading on any device but your desktop-that is, the print-optimized PDF essentially is best read on a big monitor. (I've tested it on many devices before reaching this conclusion.) So here's the big revelation: you can go to the CSDL to get other formats, including HTML, EPUB, and MOBI formats. HTML has actually been around for a long time. The last two formats are new and will be especially helpful to readers who want to "take it with them" without having it printed. You're likely to want those formats, especially if you own a Kindle, iOS, or Android device.

From my point of view, this is a great start, but I hope that it will eventually be tweaked so readers directly get links to the various formats as a bundle, much like the PDF version of the entire magazine. If there's a great article you want to read more closely, this is the way to go about getting it. Visit the CSDL. Download your favorite format. 'Nuff said. (Of course, this presumes you have an individual or institutional subscription, which you do, especially if you're reading this now.) Of course, everything I just told you only applies if you're reading this article in the current century. I can't speak to the status of our servers or the CSDL after 2067. I hope to live to 100, but I'm not making any guarantees about myself or the technology after this date. 